\title{
Aqueous Phase Lavender Leaf Mediated Green Synthesis of Gold Nanoparticles and Evaluation of its Antioxidant Activity
}

\section{Brajesh Kumar*, Kumari Smita, Karla Sofía Vizuete and Luis Cumbal}

Centro de Nanociencia y Nanotecnologia, Universidad de las Fuerzas Armadas ESPE, Av. Gral. Rumiñahui s/n Sangolqui, P.O. BOX 171-5-231B, Ecuador

"Corresponding author: Brajesh Kumar, Centro de Nanociencia y Nanotecnologia, Universidad de las Fuerzas Armadas ESPE, Av. Gral. Rumiñahui s/n Sangolqui, P.O. BOX 171-5-231B, Ecuador, Tel: (+593) 2 3989492; E-mail: krmbraj@gmail.com

Received date: April 15, 2016; Accepted date: May 10, 2016; Published date: May 15, 2016

Copyright: ( 2016 Kumar B, et al. This is an open-access article distributed under the terms of the Creative Commons Attribution License, which permits unrestricted use, distribution and reproduction in any medium, provided the original author and source are credited.

\begin{abstract}
In this paper, green synthesis of gold nanoparticles (AuNPs) using leaf extract of Lavender (Lavandula angustifolia) and their antioxidant activity was evaluated under the ambient aqueous phase condition. Assynthesized AuNPs were characterized by visual, ultraviolet-visible-near infrared (UV-vis-NIR) spectroscopy, transmission electron microscopy (TEM), and dynamic light scattering (DLS) technique. Formation of AuNPs produces an intense absorbance peak at 530 and $1055 \mathrm{~nm}$ in UV-visible spectroscopy. TEM and DLS results confirmed that the synthesized AuNPs were crystalline, polydisperse, quasi-spherical and triangular shape with an average size ranging from 34-300 nm. UV-vis-NIR, TEM, and DLS study showed that the phytochemicals from the Lavender leaf extract have dual properties of reducing and stabilizing agents. Further, AuNPs $(21.53 \%, 0.2 \mathrm{~mL})$ showed higher antioxidant activity than Lavender leaf extract (4.73\%, 0.2 mL) against 2,2-diphenyl-1-picrylhydrazyl. On looking these advantages, green synthesis of AuNPs without inert atmosphere is highly recommended for future medicinal and industrial application.
\end{abstract}

Keywords: Antioxidant activity; Nanobiotechnology

\section{Introduction}

In recent years, nanobiotechnology is one the most popular branch of nanotechnology, which received the most attention from the researchers, due to its economic and eco-friendly procedures to generate particles with a dimension smaller than $100 \mathrm{~nm}$, with specific functions [1]. Nanoparticles are synthesized by various methods such as chemical, physical, mechanical and biological [2]. The gold nanoparticles (AuNPs) is of particular interest because of its valuable application in catalysis, sensor, electronics, medicine, drug delivery, biomedical diagnostics, biolabeling, tissue/tumor imaging, photothermal therapy and immunodiagnostic [3,4].

Green synthesis of AuNPs using plant extract is recommended as an eco-friendly alternative to chemical methods that reduces the maintenance of septic environment and eliminates the generation of toxic byproducts [5]. The plant materials like Azadirachta indica leaf [6], Cinnamomum camphora leaf [7], Lantana camara flower [2], Genipa americana fruit [8], Emblica officinalis fruit [9], Capsicum baccatum fruit [10], Abelmoschus esculentus seed [11] and Plukenetia volubilis oil [12] have been reported for the extracellular synthesis of AuNPs.

Lavender (Lavandula angustifolia) is a widely distributed ornamental plant belongs to the family Lamiaceae and cultivated extensively in temperate climates of South America, Europe, and Asia. It has been traditionally considered for its very pleasant smell and a bitter taste. Its purple flowers and essential oil are used in toiletry, cosmetics, perfume, pharmaceutical, food and flavor industries. Many compounds have been detected in lavender aerial parts and flowers extract, including geraniol, linalool, linalyl acetate, ursolic acid, luteolin, umbelliferone, coumarin etc. The plant is used in traditional and folk medicines in the different parts of the world for the treatment of several skin sores, insect bites, gastrointestinal, nervous and rheumatic disorders. It also showed carminative, diuretic, antiepileptic, anti-rheumatic, pain reliever, relaxant, sedative, antioxidant, burn healing, antibacterial and anti-inflammatory properties [13,14].

So, green synthesis of nanoparticles using plant materials is of great interest. Hence, the main goal of the present study was the facile green synthesis of AuNPs using the aqueous leaf extract of Lavender. The synthesized AuNPs were characterized using ultraviolet-visible-near infrared (UV-vis-NIR) spectroscopy, transmission electron microscope (TEM), and dynamic light scattering (DLS) technique. Further, the antioxidant efficacy of AuNPs was assessed in vitro against 2,2-diphenyl-1-picrylhydrazyl ( $\left.\mathrm{DPPH}^{\circ}\right)$ and compared with the leaf extract.

\section{Materials and Methods}

\section{Materials}

Gold chloride $\left(\mathrm{AuCl}_{4}^{-}, 99.0 \%\right)$ was purchased from Spectrum, USA and $\mathrm{DPPH}^{\bullet}(>99.5 \%)$ was purchased from Sigma-Aldrich, USA. Lavender leaves were collected from the local garden of Universidad de las Fuerzas Armadas ESPE, Sangolqui, Ecuador. The thoroughly washed Lavender leaf ( $2 \mathrm{gm}$ ) was chopped and ultrasonicated in $25 \mathrm{~mL}$ of water for 3 mins. Ultrasonication was performed with ultrasonic processors (DAIGGER GE 505, $500 \mathrm{~W}, 20 \mathrm{kHz}$ ) immersed directly into the reaction solution. The operating condition was at $30 \mathrm{sec}$ pulse on/ $30 \mathrm{sec}$ pulse off time with an amplitude of $72 \%$ at $25^{\circ} \mathrm{C}$ for 3 minutes. After ultrasonication, yellow color Lavender leaf extract (LLE) was filtered using Whatman paper no. 1 and stored at $4^{\circ} \mathrm{C}$ for further use. 
Citation: Kumar B, Smita K, Vizuete KS, Cumbal L (2016) Aqueous Phase Lavender Leaf Mediated Green Synthesis of Gold Nanoparticles and Evaluation of its Antioxidant Activity. Biol Med (Aligarh) 8: 290. doi:10.4172/0974-8369.1000290

Page 2 of 4

\section{Green synthesis of AuNPs}

For the green synthesis of AuNPs, $1.0 \mathrm{~mL}$ of LLE was mixed with 10 $\mathrm{mL}$ of $0.5 \mathrm{mM} \mathrm{AuCl}_{4}^{-}$solution at room temperature $\left(22-25^{\circ} \mathrm{C}\right)$. Reduction of $\mathrm{Au}^{3+}$ to $\mathrm{Au}$ and the formation of AuNPs indicated by the appearance of a pink color after 4 hours of incubation period.

\section{Antioxidant activity of LLE and AuNPs}

The antioxidant activity of the LLE and was measured by using the $\mathrm{DPPH}^{\bullet}$ method adapted from Kumar et al., [5,12] with slight modifications. The LLE/ AuNPs (1000-200 $\mu \mathrm{L})$ or control and (1000-1800 $\mu \mathrm{L})$ of $\mathrm{H}_{2} \mathrm{O}$ was mixed with $2.0 \mathrm{~mL}$ of $0.2 \mathrm{mM}\left(\mathrm{DPPH}^{\bullet}\right)$ in $95 \%$ ethanol. The mixture was vigorously vortexed and allowed to reach a steady state in dark incubation at room temperature for 30 minutes. The absorbance of the mixture was measured spectrophotometrically at $517 \mathrm{~nm}$, and the free radical scavenging activity was calculated using Equation (1)

$$
\text { Scavenging activity }(\%)=\left(\frac{A_{0}-A_{1}}{A_{0}}\right) \times 100
$$

where $A_{0}$ is the absorbance of the control, (blank, without extract, or AgNPs) and $A_{1}$ is the absorbance in the presence of the LLE or AuNPs. The final result was expressed as \% of DPPH• free radical scavenging activity $(\mathrm{mL})$.

\section{Characterization of AuNPs}

The synthesized AuNPs were primarily characterized with the help of a UV-vis-NIR single beam spectrophotometer (Thermo Spectronic, GENESYS $^{\mathrm{TM}}$ 8, England). TEM and selected area electron diffraction (SAED) were performed in support film of $2 \%$ polyvinyl formal solution stabilized with carbon and recorded digitally (Tecnai G2 Spirit TWIN, FEI, Holland). The hydrodynamic size distributions and polydispersity index (PDI) of nanoparticles were analyzed by using DLS instrumentation (LB-550, HORIBA, Japan).

\section{Results and Discussion}

\section{Visual and UV-vis-NIR study}

The visual color change from light yellow to magenta pink after treatment of $\mathrm{Au}^{3+}$ with LLE clearly indicates the synthesis of AuNPs via reduction of $\mathrm{Au}^{3+}$ to $\mathrm{Au}$ (Figure 1, Inset). This change of solution color may be attributed to the surface plasmon resonance (SPR), a specific phenomenon which arises due to the collective oscillations of electrons in the conduction band with that of electromagnetic radiation owing to which it gives absorption in the UV-vis-NIR region [15]. In Figure 1, the time-dependent appearance of two new absorption peaks at $\lambda_{\max }=530$ and $1055 \mathrm{~nm}$ corresponding to transverse and longitudinal SPR component of spherical and triangular AuNPs. The alteration in the position of these bands gives information about the particle size, dielectric constant morphology, and adsorbed species on the surface [16,17]. Whereas LLE shows only one absorption peak at $270 \mathrm{~nm}$, it may be due to the presence of flavonoids and coumarins in LLE extract.

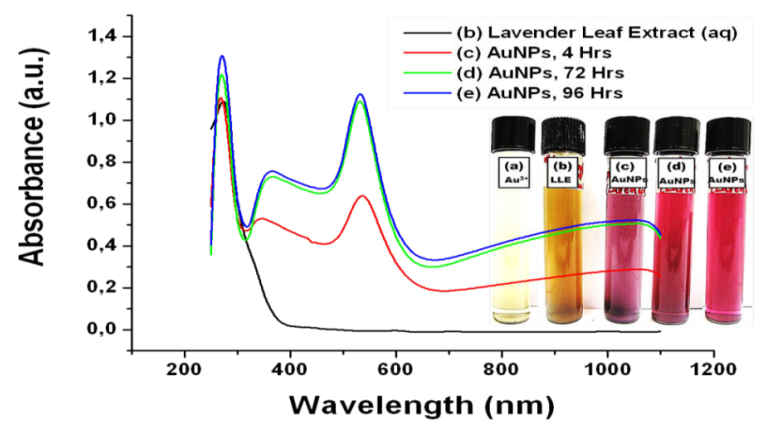

Figure 1: Visual picture and UV-vis-NIR absorbance spectra of assynthesized AuNPs at different time interval.

\section{TEM study}

The morphology, size and crystallinity of the as-synthesized AuNPs were investigated by TEM and SAED measurements. Figure 2 shows TEM images of AuNPs synthesized by using LLE. This study clearly indicates the formation of quasi-spherical and triangular particles of diameter in the range of $30-300 \mathrm{~nm}$. It could be also seen that the triangular AuNPs are coexisting with quasi spherical AuNPs, indicating that the absorption in the NIR region $(1055 \mathrm{~nm})$ and this result that was constant with UV-vis-NIR analysis. The AuNPs are considerable anisotropy, well separated from each other indicating good capping and absence of aggregation. The bright hexagonal spot in the SAED pattern (Figure 2c) from the triangular AuNPs reveals that the AuNPs are single crystalline and highly (111) oriented with the top normal to the electron beam $[18,19]$.

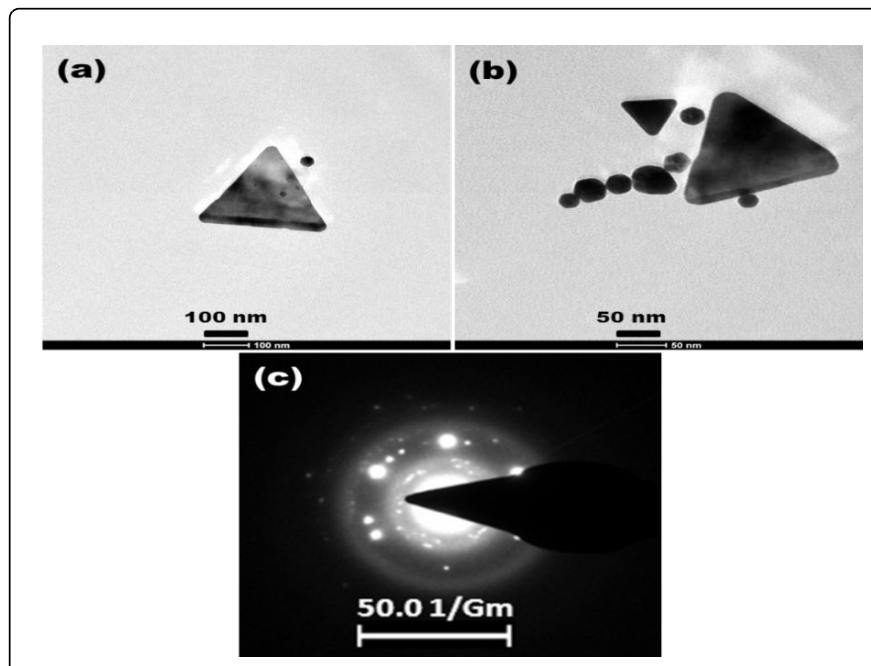

Figure 2: TEM (a-b) and SAED (c) images of AuNPs synthesized by using LLE. 


\section{DLS study}

The DLS particle size analyzer was used for determining the hydrodynamic size distribution of synthesized AuNPs and the average size was found to be $113.6 \pm 56.9 \mathrm{~nm}$ (Figure 3). The size distribution of AuNPs ranged from $34 \mathrm{~nm}$ to $400 \mathrm{~nm}$ and polydisperse in nature $(\mathrm{PDI}=0.12566)$, due to the presence of a small quasi-spherical and big triangular AuNPs. This result supports the UV-vis-NIR and TEM analysis.

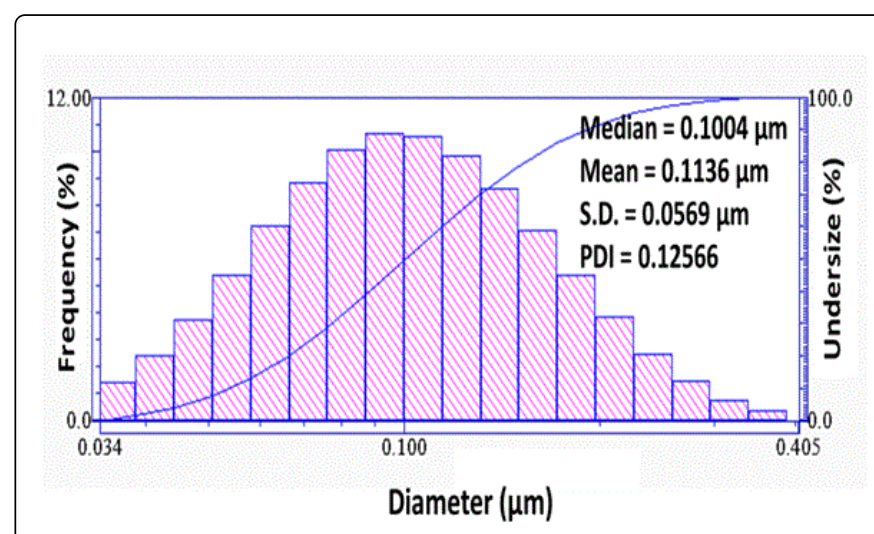

Figure 3: DLS size distribution of AuNPs synthesized by using LLE.

\section{Antioxidant study}

In normal metabolism, levels of free radicals $\left(\mathrm{O}_{2}{ }^{\bullet}, \mathrm{O}^{*}, \mathrm{HO}^{*}, \mathrm{NO} \mathrm{NO}^{*}\right)$ and antioxidants are balanced. However, the overproduction of free radicals results in oxidative damage, leading to a range of chronic diseases, such as cancer, diabetes, and inflammation. The intake of antioxidants provides protection against damage caused by free radicals. However, the use of synthetic antioxidants has been limited because of their toxicities. Therefore, research is now directed toward antioxidants of natural origin [20]. $\mathrm{DPPH}^{*}$ is a stable synthetic free radical which is readily reduced by antioxidants, either by accepting or donating electrons, during which the color of $\mathrm{DPPH}^{\bullet}$ changes from purple to yellow due to the formation of hydrazine molecules [21]. The antioxidant activity of the LLE and AuNPs was estimated by comparing the \% inhibition of $\mathrm{DPPH}^{\bullet}$ radicals (Figure 4). It can be observed that AuNPs $(21.53 \%, 0.2 \mathrm{~mL})$ show better DPPH ${ }^{\bullet}$ quenching activity as compared to $\operatorname{LLE}(4.73 \%, 0.2 \mathrm{~mL})$ at a lower concentration. The $\mathrm{DPPH}^{\bullet}$ scavenging activity of LLE increased with increasing concentrations $(4.73 \%, 0.2 \mathrm{~mL} ; 7.70 \%, 0.4 \mathrm{~mL} ; 14.09 \%, 0.6 \mathrm{~mL}$; $22.27 \%, 0.8 \mathrm{~mL}$ and $34.28 \%, 1 \mathrm{~mL}$ ) whereas, AuNPs showed the opposite trend $(21.53 \%, 0.2 \mathrm{~mL} ; 19.56 \%, 0.4 \mathrm{~mL} ; 17.18 \%, 0.6 \mathrm{~mL}$; $10.55 \%, 0.8 \mathrm{~mL}$ and $4.14 \%, 1 \mathrm{~mL}$ ) due to the less solubility of AuNPs. The antioxidant effects of the AuNPs might be the result of an active physicochemical interaction of $\mathrm{Au}$ atoms with the functional groups of the LLE [22].

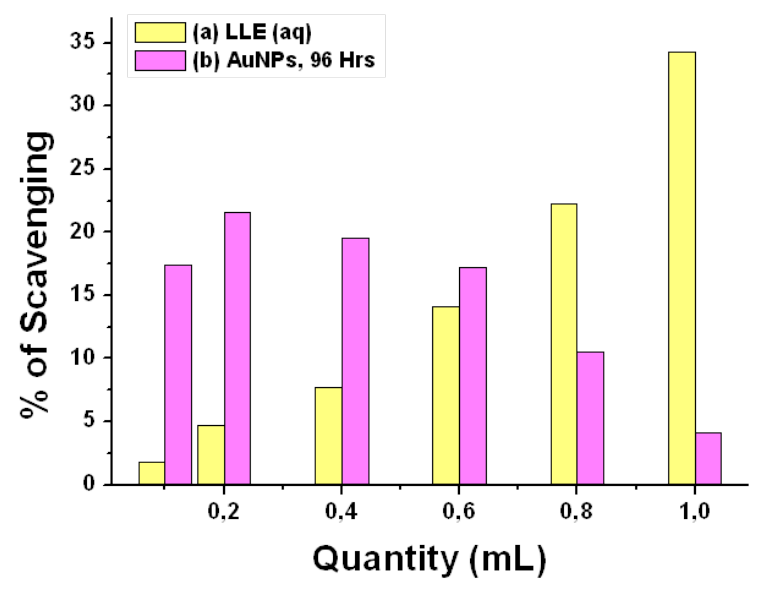

Figure 4: Antioxidant activity of (a) LLE and (b) AuNPs against $\mathrm{DPPH}^{\circ}$.

\section{Conclusion}

In conclusion, we have investigated the use of LLE as a reducing and stabilizing agent for the synthesis of AuNPs in an aqueous medium. The UV-vis-NIR, TEM with SAED and DLS results show that as synthesized AuNPs are polydisperse nature, quasi-spherical and triangular shape with an average size ranging from $34-300 \mathrm{~nm}$. It shows enhanced antioxidant activity than LLE alone at low concentration. This study provides an eco-friendly route for the synthesis and application of AuNPs with excellent reproducibility.

\section{Acknowledgments}

This scientific work has been funded by the Universidad de las Fuerzas Armadas ESPE and Prometeo Project of the National Secretariat of Higher Education, Science, Technology and Innovation (SENESCYT), Ecuador. We also thank Dr. Alexis Debut, ESPE for providing the TEM image facility.

\section{References}

1. Ahmad A, Mukherjee P, Senapati S, Mandal D, Khan MI, et al. (2003) Extracellular biosynthesis of silver nanoparticles using the fungus Fusarium oxysporum. Colloids Surfaces, B: Biointerfaces 27: 313-318.

2. Kumar B, Smita S, Cumbal L (2016) Biofabrication of nanogold from the flower extracts of Lantana camara. IET Nanobiotechnology (in press).

3. Jain PK, Huang X, El-Sayed IH, El-Sayed MA (2008) Noble metals on the nanoscale: optical and photothermal properties and some applications in imaging, sensing, biology, and medicine. Acc Chem Res 41: 1578-1586.

4. Dykman L, Khlebtsov N (2012) Gold nanoparticles in biomedical applications: recent advances and perspectives. Chem Soc Rev 41: 2256-2282.

5. Kumar B, Smita K, Seqqat R, Benalcazar K, Grijalva M, et al. (2016) In vitro evaluation of silver nanoparticles cytotoxicity on Hepatic cancer (Hep-G2) cell line and their antioxidant activity: Green approach for fabrication and application. Journal of Photochemistry \& Photobiology, B: Biology 159: 8-13. 
Citation: Kumar B, Smita K, Vizuete KS, Cumbal L (2016) Aqueous Phase Lavender Leaf Mediated Green Synthesis of Gold Nanoparticles and Evaluation of its Antioxidant Activity. Biol Med (Aligarh) 8: 290. doi:10.4172/0974-8369.1000290

Page 4 of 4

6. Shankar SS, Rai A, Ahmad A, Sastry M (2004) Rapid synthesis of Au, Ag, and bimetallic Au core-Ag shell nanoparticles using neem (Azadirachta indica) leaf broth. J Colloid Interface Sci 275: 496-502.

7. Huang J, Li Q, Sun D, Lu Y, Su Y, et al. (2007) Biosynthesis of silver and gold nanoparticles by novel sundried Cinnamomum camphora leaf. Nanotechnology 18: 105104.

8. Kumar B, Smita K, Cumbal L, Camacho J, Hernández-Gallegos E, et al (2016) One pot phytosynthesis of gold nanoparticles using Genipa americana fruit extract and its biological applications. Materials Science \& Engineering C 62C: 725-731.

9. Ankamwar B, Damle C, Ahmad A, Sastry M (2005) Biosynthesis of gold and silver nanoparticles using Emblica officinalis fruit extract, their phase transfer and transmetallation in an organic solution. J Nanosci Nanotechnol 10: 1665-1671.

10. Kumar B, Smita K, Cumbal L (2015) Phytosynthesis of gold nanoparticles using Andean Aji' (Capsicum baccatum L.). Cogent Chemistry 1: 1120982.

11. Jayaseelan C, Ramkumar R, Rahuman AA, Perumal P (2013) Green synthesis of gold nanoparticles using seed aqueous extract of Abelmoschus esculentus and its antifungal activity. Industrial Crops and Products 45: 423-429.

12. Kumar B, Smita K, Cumbal L, Debut A (2016) One pot synthesis and characterization of gold nanocatalyst using Sacha inchi (Plukenetia volubilis) oil: Green approach. Journal of Photochemistry \& Photobiology, B: Biology 158: 55-60.

13. Hajhashemi V, Ghannadi A, Sharif B (2003) Anti-inflammatory and analgesic properties of the leaf extracts and essential oil of Lavandula angustifolia Mill. J Ethnopharmacol 89: 67-71.

14. Jivad N, Rabiei Z (2014) A review study on medicinal plants used in the treatment of learning and memory impairments. Asian Pac J Trop Biomed 4: 780-789.
15. Philip D (2009) Biosynthesis of Au, Ag and Au-Ag nanoparticles using edible mushroom extract. Spectrochim Acta A Mol Biomol Spectrosc 73: 374-381.

16. Sinha $\mathrm{T}, \mathrm{Ahmaruzzaman} M$ (2016) Indigenous north eastern India fern mediated fabrication of spherical silver and anisotropic gold nano structured materials and their efficacy for the abatement of perilous organic compounds from waste water-A green approach. RSC Adv 6: 21076-21089.

17. Shankar SS, Rai A, Ahmad A, Sastry M (2005) Controlling the Optical Properties of Lemongrass Extract Synthesized Gold Nanotriangles and Potential Application in Infrared-Absorbing Optical Coatings. Chem Mater 17: 566-572.

18. Chandran SP, Chaudhary M, Pasricha R, Ahmad A, Sastry M (2006) Synthesis of gold nanotriangles and silver nanoparticles using Aloe vera plant extract. Biotechnol Prog 22: 577-583.

19. Kumar B, Smita K, Cumbal L, Debut A (2016) Extracellular biofabrication of gold nanoparticles by using Lantana camara berry extract. Synthesis and Reactivity in Inorganic, Metal-Organic, and NanoMetal Chemistry (article in press).

20. Nagajyothi PC, Cha SJ, Yang IJ, Sreekanth TVM, Kim KJ, et al. (2015) Antioxidant and anti-inflammatory activities of zinc oxide nanoparticles synthesized using Polygala tenuifolia root extract. Journal of Photochemistry and Photobiology B: Biology 146: 10-17.

21. Nakkala JR, Bhagat E, Suchiang K, Sadras SR (2015) Comparative study of antioxidant and catalytic activity of silver and gold nanoparticles synthesized from Costus Pictus leaf extract. Journal of Materials Science \& Technology 31: 986-994.

22. Kumar B, Smita K, Cumbal L, Angulo Y (2015) Fabrication of silver nanoplates using Nephelium lappaceum (Rambutan) peel: A sustainable approach. J Mol Liq 211: 476-480.
This article was originally published in a special issue, entitled: "Recent Advances in Biology \& Nanotechnology", Edited by Saurabh RamBihariLal Shrivastava 